\title{
The complexity of scaling up an mHealth intervention. SMS for Life: A Case Study from a Health Systems Integration Perspective
}

\section{Carmen Sant Fruchtman ( $\square$ c.santfruchtman@swisstph.ch )}

Schweizerisches Tropen- und Public Health-Institut https://orcid.org/0000-0002-5276-3515

\section{Selemani Mbuyita}

Independent Consultant

\section{Mary Mwanyika-Sando}

Africa Academy for Public Health

\section{Marcel Braun}

Novartis AG

Don de Savigny

Schweizerisches Tropen- und Public Health-Institut

\section{Daniel Cobos}

Schweizerisches Tropen- und Public Health-Institut

\section{Research}

Keywords: Digital Health, Scale up, Systems Thinking, Case study

Posted Date: August 17th, 2020

DOl: https://doi.org/10.21203/rs.3.rs-55573/v1

License: (1) This work is licensed under a Creative Commons Attribution 4.0 International License. Read Full License 


\section{Abstract}

Background The objective of this study was to apply systems thinking to examine the opportunities and challenges of scaling up and integrating a new electronic health technology into a complex health system. We used the implementation cycle of the supply chain management solution (SMS for Life 1.0) in Tanzania as a case study. SMS for Life was one of the earliest large-scale implementations of mHealth innovations worldwide. It aimed to bring visibility to antimalarial stock-outs through the use of SMS technology.

Methods A qualitative case-study approach was used. This included a literature review, a document review of 61 project documents, a timeline of key events and the collection and analysis of 28 interviews with key stakeholders involved in or affected by the SMS for Life programme. Using the WHO mHealth Assessment and Planning for Scale (MAPS) Toolkit as a framework, we carried out a joint thematic analysis and identified the key reasons for the discontinuation of the programme.

Results SMS for Life was reliable at scale and raised awareness of stock-outs with real-time monitoring. However, it was discontinued in 2015 after four years of a national rollout. The main reasons identified for the discontinuation were the programme's failure to adapt to the continuous changes in Tanzania's health system, the focus on stock-outs rather than ensuring appropriate stock management, and that it was perceived as costly by policy-makers.

\section{Contributions To The Literature}

- These findings contribute to the recognized gaps in the literature on how to scale up digital public health interventions in low-and middle-income countries.

- Digital health literature is often skewed towards successful studies. In this case study, we draw on the very important lessons learned about a programme that was discontinued.

- Our findings may be relevant to policy and decision-makers as well as programme planners, considering the expansion of digital health programmes to regional or national levels of service.

\section{Background}

The accelerating role of electronic information and communication technologies (ICT) in low-and middleincome countries (LMICs) is seen as one of the major opportunities for the health sector(1). Increased operational efficiencies, as well as low-cost deliveries, have led to many investments in the field $(2,3)$. There has been rapid evolution from mobile health (mHealth), which focussed mainly on the use of mobile phones, to electronic health (eHealth), or digital health, which also include further technologies(4, $5)$.

Although the interest of governments and donors has increased and more efforts are being invested in new technologies for the health sector, few programmes have managed to be successfully upscaled in 
LMICs(2). It remains the case that digital health interventions are usually undertaken in stand-alone, vertical projects and target relatively small populations $(2,6)$ rather than integrated as part of the health system. As a result, the focus of digital health initiatives has shifted towards scalability, integration, and sustainability of programmes $(6,7)$. This move has been driven by the desire of governments, partner agencies, and the private sector to invest in initiatives that provide a measurable long-term impact on the delivery of health programmes(8) and the strength of health systems.

The focus of this study is SMS for Life 1.0, a solution developed as part of a public-private partnership to address the issue of stock-outs in sub-Saharan Africa. SMS for Life was designed to make stock-outs in remote facilities more visible and reduce these with the use of SMS technology(9). One health worker in each facility was trained to send weekly SMS with the counts of stock for four ACT and quinine.

Reminders were sent automatically to the health worker's phone. If the health worker responded within 27 hours, they received credit on their phone (TZs 1,000, equivalent to USD 0.70) for personal use (pay for performance)(10). These SMS were free of charge thanks to an agreement with the mobile service provider. On a weekly basis, dashboards were compiled and sent to the District Medical Officer, to the National Malaria Control Program, other Ministry of Health, Community Development, Gender, Elderly and Children (MOHCDGEC) officials and the donors.

The programme assumed that by showing national and district managers where stock-outs occurred, these actors would arrange the redistribution of drugs between facilities or organise an emergency delivery from the medical stores department (MSD). SMS for Life was piloted and scaled-up nationwide in Tanzania in 2011. The programme monitored weekly stock levels of the official first- and second-line antimalarials used countrywide in over 5,000 government and non-governmental health facilities; it was one of the earliest large-scale mHealth innovations in LMICs. The programme ran for four years and was discontinued in 2015.

SMS for Life has been described in the literature before $(9,10)$. Barrington et al( $(9)$ presented the successful pilot results and Mikkelsen-Lopez et al (10) showed that after two years of scale-up, health facilities continued to experience severe antimalarial stock-outs. Both papers studied the programme using a quantitative approach and did not explore the reasons behind the results. With this qualitative case study, we aimed to bridge this gap and understand the innovations that SMS for Life brought to the Tanzanian health sector and also the challenges that led to its discontinuation. The lessons learned in this study should be instructive for future digital solutions aiming to go to scale and integrate into similar settings.

\section{Methods}

This was a qualitative case study of a nationwide mHealth implementation. Case study methodology allows us to look in detail to all aspects of the programme and extract the lessons learned from it (11). To conduct this case study, we used the WHO health system building blocks framework(12) to guide data 
collection from a health-systems perspective and the WHO mHealth Assessment and Planning for Scale (MAPS) toolkit as a framework to analyse and interpret this data(13).

\section{Study setting}

Tanzania's public health supply chain system serves the MOHCDGEC-operated facilities, including 20 regional vaccine stores, 137 district stores, and 6.821 service delivery points (hospitals, health centres, and dispensaries). The value of medicines and other commodities moving through the public health supply chain each year is roughly 300 billion Tanzanian shillings (TSh) (14).

The MOHCDGEC has overall responsibility for ensuring the system remains functional. System logistics are run by the MSD, a semi-autonomous organisation in $\operatorname{MOHCDGEC}(14,15)$. At the district level, the forecast and ordering of commodities is done by district pharmacists, whose supervision lies under the President's Office Regional Administration and Local Government (PORALG), as part of Tanzania's decentralized system(16).

\section{Data collection}

This case study was built on the triangulation of three data collection methods: document review, participatory observation and key informant interviews. A total of 61 documents, 3 participatory observations, and 24 interviews with 28 interviewees were included in the thematic content analysis.

\section{Document review}

We reviewed published literature, unpublished reports, evaluations, memoranda of agreement, and other available project documents to gather information on inputs, outputs, and outcomes of the programme. A data extraction tool was developed to gather key information from these.

\section{Key stakeholder interviews}

Two main groups of participating stakeholders were identified, those involved in high-level governance and design of the programme and those at frontline level (district officials and health workers). Two districts were purposively selected to conduct interviews, a high and a low-performing district. Purposive and snowball sampling were used to select the interviewees. Interview guides were developed to conduct semi-structured interviews with each group. These guides were structured following the WHO health system building blocks(12). Probes were used to elicit additional information based on the course of conversations and interviewer's observations.

CS, a female master student of public health from Spain conducted all interviews. DS, a Canadian male professor in health systems, accompanied CS in the interviews conducted in Switzerland and SM, a male 
senior social scientist holding a Master of Public Health from Tanzania co-led the interviews in Tanzania. SM led the introductions to the interviewees. Information about the study aim was shared with all participants and written or oral informed consent was collected.

28 interviewees ( 21 male, 7 female) provided free and informed consent. Three additional interviews were aimed at district and national level, but the interviewees argued having no time for the interview or the phone number provided didn't work. Table 1 describes the organization and level of these, defined by the geographical reach of their work.

21 interviews were conducted face-to-face in the place of work of the interviewees. A confidential and quiet place was always found to discuss the study questions. The other seven participants were interviewed over the phone or Skype. The average duration of these interviews was one hour. Three interviews were conducted with two interviewees simultaneously. No interview was repeated. Sampling was stopped once data saturation was reached.

\section{Data analysis}

Interviews were audiotaped, transcribed and translated, when necessary, into English. Researchers' interview notes were typed and organised into summaries of each interview. This collation encouraged immersion in the data to aid analysis and reflection from an early stage during data collection. CS and SM both participated in this process.

Transcripts and interview summaries were shared, when possible, with the study participants. Nevertheless, no feedback was received from these.

All interviews were coded and analysed by CS, who was supervised by DC and DS. CS conducted a joint thematic analysis of the transcripts and collated documents using a directed approach with predefined categories of the WHO MAPS toolkit (Table 2) in Nvivo12. Findings were validated by the wider research team.

\section{Ethical issues}

The study received approval from ethics committees at the Swiss Tropical and Public Health Institute, the Tanzania IRB (NIMR/HQ/R.8a/Vol.IX/2767) and COSTECH. All participants in the study signed a consent form or gave oral consent after being given a written study information sheet and a verbal explanation of the consenting process.

\section{Results}


We used the domains from WHO MAPS toolkit to structure the main findings of our qualitative study (summarised in Table 3)(13).

The high costs of the programme (50'000 USD/month), combined with its focus on a single disease, its failure to adapt to the arrival of competitor systems to Tanzania, and the lack of continuity between ministerial leaders, were shown to be the main reasons for its discontinuation. Most interviewees expressed that SMS for Life was well aligned with the country's priorities when it was implemented because the malaria burden was high and delivering first-line drugs was essential and a challenge for the country. However, the interviewees stated that focussing on stock-outs and not on appropriate stock management fell short of solving the problem and caused some political challenges as no-one wanted to report bad news.

In terms of partnerships, SMS for Life aimed to engage the right partners before rolling out the programme. Its internally-approved, not publicly available implementation guidelines stated that: "before the SMS for Life project is rolled out in any country, it is vital that the key stakeholders involved in Malaria Prevention and Control, and the relevant people responsible for drug distribution and management are informed about, and involved in, the project." However, the opinions of the interviewees differ. A substantial number of interviewees mentioned that not all key stakeholders were involved in the design and deployment of the programme. Some examples given that were not engaged were district pharmacists, MSD or officials at the regional level.

SMS for Life had strong champions during the pilot, but there were many changes in the government during the scale-up, which led to changes in priorities.

"Changes in leadership, changes in the background in the people in charge, changes in the priorities, this all influences sustainability of programmes." District Medical Officer

With changes in leadership, questions were also raised regarding the costs of the programme. Most interviewees agree that the main reason for discontinuation was that the programme was too expensive to cover just one disease and that it was not possible to justify why a substantial share of the MoH's budget should be dedicated to the supply chain of one programme and not others.

"The system was very expensive. The government asked itself should I pay for a system that costs over $500{ }^{`} 000$ USD/year or buy drugs for that amount of money?" External researcher

Despite some challenges being identified in the political arena, the programme was well-received among health facility personnel and it demonstrated that health facilities could use SMS technologies easily and provide continuous stock reporting(17).

The simplicity of sending a weekly SMS was a contrast to the complexity and delays of responding to stock-outs using the quarterly paper system. The response by the health system to the stock-outs SMS for Life was reporting, was not properly designed. Interviewees at the highest level of the national 
institutions explained that the response to stock-outs was a big challenge of SMS for Life. The reasons for the lack of response when a stock-out was reported through SMS for Life are shown in Table 4.

Nevertheless, the evidence found, including the $\mathrm{WHO}$ MoH Service and Availability Readiness Assessment (SARA), showed that antimalarial stock-outs were occurring less frequently in most parts of the country during the time of SMS for Life, especially from 2014(18-20). The main reason stated by most interviewees for this improvement were modifications in the procurement system that were occurring in parallel to SMS for Life. Vertical programmes (e.g. national malaria control programme) and health facilities were allowed to receive funds directly to purchase drugs, instead of having to go through the MSD. The purchase of drugs was decentralised and direct delivery was introduced. As part of this substantial initiative to improve the stock situation, the electronic Logistics Management Information System (eLMIS) was launched and the Logistics Management Unit (LMU), within the MoH, was created to manage the system(20).

In addition, shortly after the scale-up of SMS for Life, other supply chain information systems entered the Tanzanian landscape, including ILS Gateway. This programme had a similar objective and was also an SMS-based solution, but included 20 different products and had lower running costs. However, users reported this second system was more difficult to use.

The coexistence of both programmes with similar objectives but funded by different donors led to competition between them, even if thought to be complementary. ILSGateway and SMS for Life were making each other redundant. In a Global Fund Audit the following was reported: "Although developed for different purposes and meant to be complementary, some of the developed systems have duplicative functions, e.g. the SMS4life and ILS gateway (costing USD 600,000 and 60,000 annually, respectively) collect similar information. There are plans to discontinue SMS4life under the new grants." (20)

SMS for Life was a stand-alone system, so the information was not flowing to any other information system in the country. This was reported in almost all interviews as a big challenge for the sustainability of the programme.

Several information systems have been implemented since SMS for Life was scaled-up. MSD works with Epicore 9 to track the logistics of their procedures, while the health system has had different independent systems to track stock since the pull system was implemented: Request\&Requisition (R\&R) paper forms, end-use verification forms, tracer forms, ILS Gateway, DHIS2, and, most recently, eLMIS(21).

These systems increased the complexity of taking action against stock-outs, as they were often reporting contradictory results. To harmonize Tanzania's digital systems, including the supply chain information systems, the country launched its national e-health strategy in 2013(21).

\section{Discussion}


The overarching purpose of this study was to contribute to a growing body of literature examining digital health interventions, including the challenges involved in integrating and sustaining such interventions in a complex health system. This paper focusses on a long-running national-scale mHealth solution, which was eventually discontinued. Publications detailing such programmes are often biased towards positive results. A recent study by Al-Durra et al(22) examined non-publication rates in digital health and concluded higher non-reporting rates than in other fields. These results are worrying considering the large number of pilots being conducted in digital health that never reach full scale(7). The learnings that can be taken from failed systems integration attempts are crucially important for the success of future programmes.

We chose to study SMS for Life 1.0 because it was one pilot that had managed to overcome the initial challenges and reached full national scale in 2011, a time when digital health was still emerging in LMICs and the majority of pilots failed to reach this scale $(1,22)$. However, despite initial success, the programme was discontinued without a final evaluation in 2015.

During the rollout, the technology of SMS for Life proved to be technically reliable and well appreciated. The programme collected real-time data in rural health facilities at a time when this was uncommon(9) and ultimately achieved its stated primary objective to provide visibility of antimalarial stock-outs.

Our analysis suggests that this narrow objective fell short of what was required in Tanzania and the programme would have been improved by aiming to reduce stock-outs, rather than just aiding visibility. A change in aim would have encouraged not only the reporting but also the action necessary to solve stockouts by the health system. The literature describes this output-driven set-up as a common shortfall of digital health projects being implemented around 2010(23). In 2011, and as a response of this, the Bellagio Statement on eHealth Evidence was written, calling for better evaluation and research of digital health programmes (24).

SMS for Life was built within the national malaria control programme and failed to consolidate and communicate with other programmes or departments (e.g. MSD, HMIS Department) (25-27). In the early days of digital health, this was a common shortcoming where many digital health solutions were developed in isolation and focussed on a single challenge $(25,28,29)$. For future digital health programmes, identifying a process that could benefit more than one healthcare problem, would ensure greater stakeholder buy-in and set up the programme for prolonged success.

During the scale-up of the programme, many internal changes occurred in Tanzania that impacted the sustainability of SMS for Life, including changes in government, treatment policies, and supply chain systems. One of the major changes was the introduction of new logistics management information systems. At the health facility level, the coexistence of different systems with similar objectives confused and at national-level it caused competition between programmes.

With time, champions of SMS for Life transitioned to other government positions and thus support for the programme's implementation waned. Meanwhile, the ILS Gateway gained relevance in the new 
government. ILS Gateway was perceived as a more cost-effective solution, although an economic evaluation was never conducted to compare both systems. Despite this, most interviewees considered SMS for Life a more reliable technology. Iribarren et al (30) report this lack of economic evaluation and comparison within programmes in their systematic review and advocate for the use of economic methods to undertake informed decisions. The more recent digital health guidelines published by WHO also highlight the need to conduct detailed costing exercises(31).

In Tanzania, the MoH had initially committed to take over the costs of SMS for Life but this never transpired. When it came to taking these costs into its own budget, the programme was discontinued. This has been reported before, as there is often a large gap between the initial commitment and the actual realisation of assuming the costs(23).

Additionally, SMS for Life lacked a monitoring and evaluation scheme, and no implementation research was conducted to assess the performance after scale-up. The WHO digital health guidelines also address this and call for more effectiveness studies to monitor performance and behavioural performance or user engagement for the benefit of future programmes.

Agile management techniques are now gaining momentum and we believe SMS for Life would have benefited tremendously from their application to adapt to the on-going changes in Tanzania.

Implications for future digital health solutions at scale

This study highlights the need to rethink interventions when going to scale and to highlight these in the literature for future implementation processes to learn from. Agile project management schemes(32), cost evaluations and system approaches are important tools in achieving sustainable programmes(33). We also encourage the use of the MAPS toolkit for project managers to provide them with resources to assess the maturity of their mHealth programme and stage-based strategies for scale-up(13).

\section{Limitations}

There is a level of subjectivity involved in qualitative case studies and this should be considered when interpreting the study findings. By applying different methodologies, we aimed to triangulate results and overcome some of the limitations associated with each methodology.

\section{Conclusion}

It is important to recognise the many successes and innovations that SMS for Life brought to Tanzania and to mHealth globally. The programme developed and introduced an SMS-based solution to address the serious antimalarial stock-out problem. However, it failed to address complex systems and individual, interpersonal, and institutional factors in programme planning, which ultimately led to its discontinuation.

To bridge this gap, we suggest the use of holistic methodologies and detailed costing exercises. These would help governments to carefully plan the programme to ensure its affordability right from its early 
stages. The programme would also have benefited from a health systems approach that would have guided programme managers to better navigate complex adaptive health systems $(34,35)$. These learnings are echoed in the steps from the WHO view of systems thinking and the most recent WHO digital health guidelines $(12,31)$.

This research may be relevant to policy and decision-makers as well as programme planners, considering the expansion of digital health programmes to regional or national levels of service. We strongly suggest making use of the tools now available and include scale-up frameworks from the beginning of the intervention design.

Finally, despite the discontinuation of SMS for Life 1.0, key learnings can be taken forward to ensure the success of future programmes and ultimately improve healthcare for all.

\section{Abbreviations}

eHealth

electronic health

eLMIS

electronic Logistics Management Information System

HMIS

health management information system

ICT

information and communication technologies

LMICs

low-and middle-income countries

MAPS

WHO mHealth Assessment and Planning for Scale

mHealth

mobile health

MOHCDGEC

Ministry of Health, Community Development, Gender, Elderly and Children

MSD

medical stores department

PORALG

President's Office Regional Administration and Local Government

SARA

Service and Availability Readiness Assessment

TSh

Tanzanian shillings

\section{Declarations}


Ethics approval and consent to participate: Granted by the National Institute for Medical Research in Tanzania (NIMR/HQ/R.8a/Vol.IX/2767). Written or oral informed consent to participate in the study was obtained from all participants, and permission was granted to use non-identified qualitative data for publication

Consent for publication: not applicable.

Availability of data and materials: The transcripts that were used for the development of this manuscript can be requested from the corresponding author.

Competing interests: None declared.

Funding: This work was made possible by a grant of Novartis Social Business, Switzerland

Authors' contributions: CS designed the study, conducted all interviews, led the analysis and writing of this paper. SM co-led the data collection and interpretation of the data, as well as contributed to the review of the manuscript. DC and DDS made substantial contributions to the design of the work, data analysis and interpretation of the data. All authors have read and approved the final version of this manuscript.

Acknowledgements: Editorial assistance was provided by Prescript Communications Ltd.

\section{References}

1. Franz-Vasdeki J, Pratt BA, Newsome M, Germann S. Taking mHealth Solutions to Scale: Enabling Environments and Successful Implementation. Journal of Mobile Technology in Medicine. 2015;4(1):35-8.

2. Qiang CZ, Yamamichi M, Hausman V, Miller R, Altman D. Mobile Applications for the Health Sector.98.

3. eHealth WHOGOf, World Health O. MHealth: new horizons for health through mobile technologies. Geneva: World Health Organization; 20112011.

4. Labrique A, Vasudevan L, Mehl G, Rosskam E, Hyder AA. Digital Health and Health Systems of the Future. Global health, science and practice. 2018;6(Suppl 1):S1-s4.

5. Who. Classification of digital health interventions v1.0. WHO; 2018 2018/04//.

6. Long L-A, Pariyo G, Kallander K. Digital Technologies for Health Workforce Development in Low- and Middle-Income Countries: A Scoping Review. Global health, science and practice. 2018;6(Suppl 1):S41-S8.

7. Huang F, Blaschke S, Lucas H. Beyond pilotitis: taking digital health interventions to the national level in China and Uganda. Globalization and health. 2017;13(1):49.

8. Labrique AB, Wadhwani C, Williams KA, Lamptey P, Hesp C, Luk R, et al. Best practices in scaling digital health in low and middle income countries. Globalization and health. 2018;14(1):103. 
9. Barrington J, Wereko-Brobby O, Ward P, Mwafongo W, Kungulwe S. SMS for Life: a pilot project to improve anti-malarial drug supply management in rurual Tanzania using standard technology. Malaria J. 2010;9(298).

10. Mikkelsen-Lopez I, Shango W, Barrington J, Ziegler R, Smith T, deSavigny D. The challenge to avoid anti-malarial medicine stock-outs in an era of funding partners: the case of Tanzania. Malaria J. 2014;13:181.

11. Hyett N, Dr AK, Dr VD-S. Methodology or method? A critical review of qualitative case study reports. International Journal of Qualitative Studies on Health and Well-being. 2014;9(1):23606.

12. de Savigny D, Adam T. Systems Thinking for Health Systems Strengthening. Geneva: World Health Organization; 2009.

13. United Nations F, Johns Hopkins University Global mHealth I, Special Programme of Research D, Research Training in Human R, World Health O, World Health O, et al. The MAPS toolkit: mHealth assessment and planning for scale2015 2015.

14. Mwencha M, Rosen JE, Spisak C, Watson N, Kisoka N, Mberesero H. Upgrading Supply Chain Management Systems to Improve Availability of Medicines in Tanzania: Evaluation of Performance and Cost Effects. Global health, science and practice. 2017;5(3):399-411.

15. Mikkelsen-Lopez I, Cowley P, Kasale H, Mbuya C, Reid G, de Savigny D. Essential medicines in Tanzania: does the new delivery system improve supply and accountability? Health Syst (Basingstoke). 2014;3(1):74-81.

16. Printz N, Amenyah J, Serumaga B, Wyk DV. Tanzania: Strategic Review of the National Supply Chain for Health Commodities.; 2013.

17. Marchand D. SMS FOR LIFE (C): SUSTAINING THE INITIATIVE AND LEVERAGING ITS SOCIAL AND BUSINESS VALUE FOR NOVARTIS. 2012 2012/09/03/.

18. Health Mo, Social Welfare/Tanzania, Ministry of Health/Zanzibar, National Bureau of Statistics/Tanzania, Office of Chief Government Statistician/Tanzania, ICF International. Tanzania Service Provision Assessment Survey 2014-2015. Dar es Salaam, Tanzania: MoHSW/Tanzania, MoH/Tanzania, NBS/Tanzania, OCGS/Tanzania, and ICF International; 2016.

19. Tanzania Ministry of H, Social W. Service and Availability Readiness Assessment Tanzania 2012. $20132013 / 07 / /$.

20. Twaweza. More money alone will not help stock outs. 2014 2014/05/20/.

21. Ministry Of H, Social Welfare T. Tanzania National eHealth Strategy 2012-2018. 2013 2013/05/21/.

22. Al-Durra M, Nolan RP, Seto E, Cafazzo JA, Eysenbach G. Nonpublication Rates and Characteristics of Registered Randomized Clinical Trials in Digital Health: Cross-Sectional Analysis. Journal of medical Internet research. 2018;20(12):e11924.

23. Labrique A, Vasudevan L, Weiss W, Wilson K. Establishing Standards to Evaluate the Impact of Integrating Digital Health into Health Systems. Global Health: Science and Practice. 2018;6(Supplement 1):S5-S17. 
24. Fraser H, Bailey C, Sinha C, Mehl G, Labrique AB. Call to action on global eHealth evaluation: consensus statement of the WHO Global eHealth Evaluation Meeting, Bellagio, September 2011. Bellagio, Italy: Bellagio eHealth Evaluation Group; 2011. The Bellagio eHealth Evaluation Group. 2011.

25. Alami H, Gagnon M-P, Fortin J-P. Digital health and the challenge of health systems transformation. mHealth. 2017;3:31.

26. Feroz A, Perveen S, Aftab W. Role of mHealth applications for improving antenatal and postnatal care in low and middle income countries: a systematic review. BMC health services research. 2017;17(1):704.

27. Rokicki S, Fink G. Assessing the reach and effectiveness of mHealth: evidence from a reproductive health program for adolescent girls in Ghana. BMC Public Health. 2017;17(1):969.

28. Barker PM, Reid A, Schall MW. A framework for scaling up health interventions: lessons from largescale improvement initiatives in Africa. Implementation Science. 2016;11:12.

29. Greenhalgh T, Russell J. Why Do Evaluations of eHealth Programs Fail? An Alternative Set of Guiding Principles. PLoS Medicine. 2010;7(11).

30. Iribarren SJ, Cato K, Falzon L, Stone PW. What is the economic evidence for mHealth? A systematic review of economic evaluations of mHealth solutions. PloS One. 2017;12(2):e0170581.

31. Organization WH. WHO guideline: recommendations on digital interventions for health system strengthening. Geneva: World Health Organization; 20192019.

32. Wilson K. Agile research to complement agile development: a proposal for an mHealth research lifecycle I npj Digital Medicine. 2018.

33. Greenhalgh T, Papoutsi C. Spreading and scaling up innovation and improvement. BMJ. 2019;365:I2068.

34. Cobos Munoz D, de Savigny D, Sorchik R, Bo KS, Hart J, Kwa V, et al. Better data for better outcomes: the importance of process mapping and management in CRVS systems. BMC Med. 2020;18(1):67.

35. de Savigny D, Adam T, Campbell S, Best A. Systems thinking: What it is and what it means for health systems. In: de Savigny D, Adam T, editors. Systems thinking for health systems strengthening. Geneva: WHO; 2009. p. 37-48.

\section{Tables}

Table 1: Work organization and level of interviewees 


\begin{tabular}{|l|c|c|}
\hline Stakeholder organisation & Level & Interviewees \\
\hline SMS for Life project management & Global/National & 4 \\
\hline Donor SMS for Life & Global & 3 \\
\hline Other supply chain donors & Global/National & 2 \\
\hline Ministry of Health & District & 3 \\
\hline National Malaria Control Programme & National & 3 \\
\hline External advisor Ministry of Health & Global/National & 2 \\
\hline Medical Stores Department (MSD) & National & 1 \\
\hline District Health Management Team & District & 3 \\
\hline Health personnel reporting with SMS & Health facility & 3 \\
\hline Civil society & National & 2 \\
\hline External researcher & National & 2 \\
\hline
\end{tabular}

Table 2: Domains explored during thematic content analysis using MAPS toolkit

\begin{tabular}{|l|l|}
\hline MAPS Domain & Theme \\
\hline Groundwork & Were the policy and technical environments in the country assessed before scale-up? \\
\hline Partnerships & Were specific product champions established among core partners? \\
\hline Financial health & Were the potential economic costs of scaling up the technology forecasted? \\
\hline Technology \& architecture & Were relevant steps taken to ensure interoperability with relevant information systems? \\
\hline Operations & Were training programmes developed to train end-users and secondary users? \\
\hline Monitoring \& evaluation & Were appropriate resources allocated to monitoring and evaluation during scale-up? \\
\hline
\end{tabular}

Table 3: Summary of main themes identified in the thematic analysis across the MAPS domains 


\begin{tabular}{|c|c|c|}
\hline $\begin{array}{l}\text { MAPS } \\
\text { Domain }\end{array}$ & Main themes identified & \\
\hline & Positive & Negative \\
\hline Groundwork & $\begin{array}{l}\text { 1. Very successful pilot } \\
\text { 2. The goal of the programme aligned with the } \\
\text { country's priorities }\end{array}$ & $\begin{array}{l}\text { 1. SMS for Life was short in objective-setting (focus on stock-out } \\
\text { visibility and not on an appropriate response to stock-outs) }\end{array}$ \\
\hline Partnerships & $\begin{array}{l}\text { 1. SMS for Life aimed to engage with all key } \\
\text { stakeholders }\end{array}$ & $\begin{array}{l}\text { 1. Not all key stakeholders were involved in the design and } \\
\text { deployment (e.g district pharmacists) } \\
\text { 2. Narrow partnership scope focussed on limited commodities } \\
\text { for a single disease control programme } \\
\text { 3. No inclusion of Zonal or National MSD in the system } \\
\text { 4. Lack of ownership at MSD and district level led to a lack of } \\
\text { action when stock-outs were reported } \\
\text { 5. Changes in government, ministerial leadership and political } \\
\text { agendas led to the loss of SMS for Life's momentum } \\
\text { 6. This loss of momentum was strongly influenced by the arrival } \\
\text { of competitor mHealth solutions }\end{array}$ \\
\hline $\begin{array}{l}\text { Financial } \\
\text { health }\end{array}$ & $\begin{array}{l}\text { 1. SMS for Life project managers described the } \\
\text { system as a very low cost solution as it didn't need } \\
\text { any maintenance or technical support }\end{array}$ & $\begin{array}{l}\text { 1. The costs of the programme were stated as one of the main } \\
\text { reasons for discontinuation although no real costing was done } \\
\text { 2. It was difficult for the government to allocate a substantial } \\
\text { share of its budget to malaria commodities and not to others } \\
\text { 3. Main drivers of the programme's costs were: SMS and health } \\
\text { worker incentives (pay-for-performance) }\end{array}$ \\
\hline $\begin{array}{l}\text { Technology } \\
\& \\
\text { architecture }\end{array}$ & $\begin{array}{l}\text { 1. Real-time data in rural health facilities in a time } \\
\text { when this was uncommon } \\
\text { 2. Described as a user-friendly system } \\
\text { 3. Technology included quality checks } \\
\text { 4. Interoperability within mobile network operators } \\
\text { was an innovation and at the same time challenge } \\
\text { for the programme } \\
\text { 5. Technology was an innovation for Tanzania and } \\
\text { mHealth globally }\end{array}$ & $\begin{array}{l}\text { 1. Lack of adaptability of the technology to new circumstances } \\
\text { in the country } \\
\text { 2. Data server and hosting in the United Kingdom seen as a } \\
\text { political challenge } \\
\text { 3. Lack of interoperability with the national health management } \\
\text { information system (HMIS) } \\
\text { 4. No change or improvement in the user interface between } \\
2009 \text { and } 2015\end{array}$ \\
\hline Operations & $\begin{array}{l}\text { 1. SMS for Life trained health facility personnel to } \\
\text { store commodities more efficiently, these changes } \\
\text { are still visible today }\end{array}$ & $\begin{array}{l}\text { 1. The scale-up planning only included the organization of } \\
\text { training } \\
\text { 2. Lack of response from the health system in case of stock-outs } \\
\text { (see Table 4) } \\
\text { 3. High turnover of personnel at the health facilities caused a } \\
\text { knowledge loss of the programme, as only one person was } \\
\text { trained per facility. This led to high attrition rates from the } \\
\text { system } \\
\text { 4. No continuing training plans }\end{array}$ \\
\hline
\end{tabular}


Monitoring

\& evaluation

1. Antimalarial stock situation improved during the years, mainly due to other changes in Tanzanian supply chain system (e.g. MSD Direct Delivery system).
1. No monitoring and evaluation framework

2 . One external evaluation conducted in 2013 reported several challenges that were never addressed

Table 4: Reasons stated for the lack of action to solve stock-outs at district level

1) Commodities claimed not to be available at MSD, often due to delays in procurement

2) Lack of resources for transport between health facilities or to pick up drugs at MSD

3) Unwillingness by the health facilities to reallocate their surplus stock due to lack of confidence in a replenishment delivery

4) Lack of ownership of district leadership of the programme, which led to a lack of use of the collected data

\section{Figures}

1. SMS for Life was a scalable and reliable technology that showed it was possible to collect real-time data in rural health facilities in Tanzania;

2. SMS for Life failed to adapt to the constant changes in the health system and lost its momentum and constituency of support;

3. The programme was siloed within the National Malaria Control Programme;

4. Financial constraints as well as changes in country priorities led to its discontinuation in 2015.

\section{Figure 1}

Lessons learned of SMS for Life scale-up in Tanzania

\section{Supplementary Files}

This is a list of supplementary files associated with this preprint. Click to download.

- ISSMCOREQChecklist.pdf 
- ISSMCOREQChecklist.pdf

Page 17/17 